\title{
On Human Autonomic Nervous Activity Related to Behavior, Daily and Regional Changes Based on Big Data Measurement via Smartphone
}

\author{
Makoto Komazawa ${ }^{1,2}$, Kenichi Itao ${ }^{2,3}$, Hiroyuki Kobayashi ${ }^{3}$, Zhiwei Luo ${ }^{4}$ \\ ${ }^{1}$ Graduate School of System Informatics, Kobe University, Kobe, Japan \\ ${ }^{2}$ WINFrontier Co. Ltd., Tokyo, Japan \\ ${ }^{3}$ JUNTENDO University, Tokyo, Japan \\ ${ }^{4}$ Organization of Advanced Science and Technology, Kobe University, Kobe, Japan \\ Email: makoto.komazawa@winfrontier.com
}

Received 6 May 2016; accepted 12 June 2016; published 15 June 2016

Copyright (C) 2016 by authors and Scientific Research Publishing Inc.

This work is licensed under the Creative Commons Attribution International License (CC BY). http://creativecommons.org/licenses/by/4.0/

\begin{abstract}
This research uses a large amount of autonomic nervous system data (approximately 100,000 entries) to investigate the relationship between human autonomic nervous activity and behaviors, daily and regional changes. Data were measured via a heart rate variability analysis system that utilizes the camera of smartphones. This system was developed by the authors during previous research. The relations between autonomic nervous system and behaviors, total power and sympathetic nervous activity were found to rise after waking, while during leisure time, the total power rises and sympathetic nervous activity is inhibited. Concerning the relationship between autonomic nervous system and day of the week, it was found that total power decreases from the middle through the latter part of the week (namely, Wednesday, Thursday, and Friday), while it rises on Saturday, while the sympathetic nervous activity is suppressed on Saturday. Regarding the relationship between autonomic nervous system and region, it was found that total power is lower in the Kanto region of Japan than in others. This study also shows statistical proof (using a large amount of measurement data) to ideas held by the public for years. Thus, the data can be considered meaningful to the society, and the authors hope that it helps to improve work-life balance.
\end{abstract}

\section{Keywords}

Heart Rate Variability, Autonomic Nervous System, Large Amount of Measurement Data, Activity, Day of the Week, Region 


\section{Introduction}

It has long been recognized that modern society is stressful. If human beings are subjected to stress for a long period, the functions of autonomic nervous system and the endocrine system, which controls the adrenocortical hormone, will be seriously influenced [1]. The autonomic nervous system controls the balance between the sympathetic nerve activity, which responses for maintaining the tension and excitement, and the parasympathetic nerve activity, which responses for maintaining relaxation. Therefore, it is very important for self-management to routinely recognize the state of our autonomic nervous system during everyday life [2].

The typical non-invasive technique for measuring autonomic nervous system uses a small, specialized heart rate sensor [3], or a fingertip pulse wave sensor [4]. These devices are used to measure RR interval (heartbeat interval) and peak interval (a value corresponding to the RR interval that is detected from the pulse waveform) [5], whereupon heart rate variability analysis is performed to calculate sympathetic nervous and parasympathetic nervous activity indicators [6]. These systems use Fast Fourier Transform (FFT) [7] to calculate the autonomic nervous activity from RR interval data in one to five minutes.

However, all these products use extremely expensive, specialized sensors and systems to measure RR intervals and pulse wave peak intervals. Thus, the hurdles to their use by the general public are high. Because of this, measurement of autonomic nervous system conditions has been limited to specialized facilities such as hospitals.

During previous research, authors developed a simple and precise measurement system that does not rely on specialized devices, but utilizes the camera of smartphones sold on the general market [8]. In this system, the device camera is placed on the tip of the finger for a short amount of time (just over 30 seconds), where it detects the pulse waveform peak interval from luminance changes in blood flow. Then, heart rate variability analysis is performed to measure the detailed conditions of the autonomic nervous system, namely, its balance and amount of activity (total power).

This system is currently being put to use by approximately 1,000,000 users (as of March 2016) [11] as an App for their iPhone (Apple Inc.) [9] or Android device (Google Inc.) [10].

Up to this point, autonomic nervous system measurements have been mainly conducted at hospitals, laboratories, and other facilities, using specialized sensors and equipment. Thus, the number of possible measurement subjects was limited to few hundred people at most. And as measurements were conducted under a particular set of circumstances, they cannot be considered an accurate representation of autonomic nervous system in daily life.

The system utilized in this study, however, is able to easily measure a large amount of data at any time, any location, and after any activity, giving researchers an understanding of autonomic nervous system conditions under everyday circumstances.

The authors used this system in previous research to investigate the relationship between autonomic nervous system and age and BMI, based on approximately 100,000 entries of autonomic nervous system data. This study found that the autonomic nervous activity decreases significantly as age and BMI increase [12]. The authors also published a study on the diurnal variation of autonomic nervous system, based on approximately 100,000 entries of autonomic nervous system data [13]. The results of these studies are consistent with results obtained using specialized sensors and measurement equipment.

This research uses an unprecedented set of approximately 100,000 entries of data on the autonomic nervous system and analyzes it according to the three parameters below.

- The relationship between autonomic nervous system and activity

- The relationship between autonomic nervous system and day of the week

- The relationship between autonomic nervous system and region

\section{Methods}

This study employed a heart rate variability analysis system utilizing the camera of smartphones [8]. In this system, the smartphone camera is placed against the tip of the finger, where it continuously acquires data on the luminance of the skin. If the finger is lifted from the camera, the system displays a warning message. A pulse wave is derived from the changes in luminance, and the peak interval (corresponds to the RR interval) is detected from that pulse waveform. Then, frequency analysis is performed on peak interval fluctuations to calculate the autonomic nervous system indicator. This system is outlined in Figure 1. 

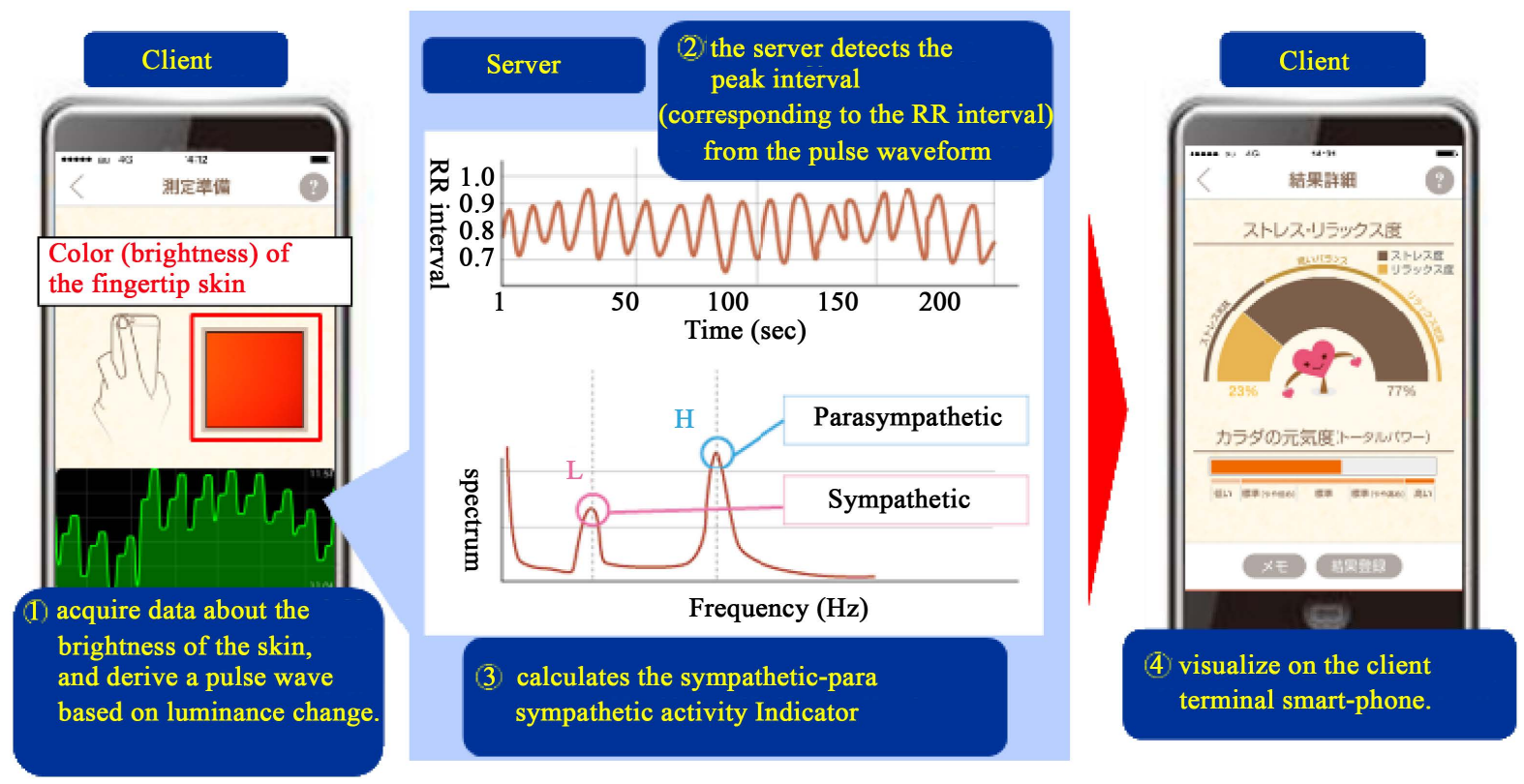

Figure 1. System outline.

The frequency analysis conformed to the procedure described in [6], with the low frequency component (LF) calculated as $0.04 \mathrm{~Hz}-0.15 \mathrm{~Hz}$, and the high frequency component (HF) calculated as $0.15 \mathrm{~Hz}-0.4 \mathrm{~Hz}$.

LF/HF values are used as indicators of sympathetic nervous activity, as well as indicators of tension, stimulation, and stress [6].

The sum of the LF and HF values are called the total power (TP), and it serves as an indicator of the autonomic nervous activity [6]. The total power is said to be correlated with fatigue, with smaller values indicating higher levels of fatigue [14].

This paper analyzes the autonomic nervous system data of 27,307 subjects (6394 males and 20,913 females). Measurement data was used with the consent of the subjects, in accordance with the ethics regulations of WIN Frontier Co., Ltd. The data was measured during April 2015 to September 2015.

Subject age (in tens of years) and sex are displayed in Table 1. IBM SPSS Statics Version 22 was used for this study's statistical processing. The significance level was set to $5 \%$.

\section{The Relationship between Autonomic Nervous System and Activity}

In this section, a relationship (under everyday circumstances) between autonomic nervous system and activity is shown. In the research conducted up to this point, there have been few reports analyzing trends (based on a large amount of data) in autonomic nervous system for different activities of everyday life.

\subsection{The Relationship between Total Power and Activity}

In this section, the relationship between total power and activity is investigated. Information on the measurement data used in the study's analysis is given in Table 2. It is said that performing logarithmic transformation on total power (an indicator of autonomic nervous system) increases its normality [15], so logarithmic transformation was performed on the total power values (LnTP) for all the measurement data. The resulting values were then divided into eight groups based on activity, and the differences between groups were investigated by performing a Games-Howell multiple comparison procedure. The results are given in Figure 2 and Table 3. Total power was found to be significantly higher after waking and during leisure time, a trend that was also observed when analyzing data separately by sex.

It has been observed in previous research that the amount of autonomic nervous system rises before and after waking due to diurnal variation in autonomic nervous system [16], a trend that is consistent with observations made in this study. What's more, total power was found to rise during leisure time, suggesting that leisure is ef- 


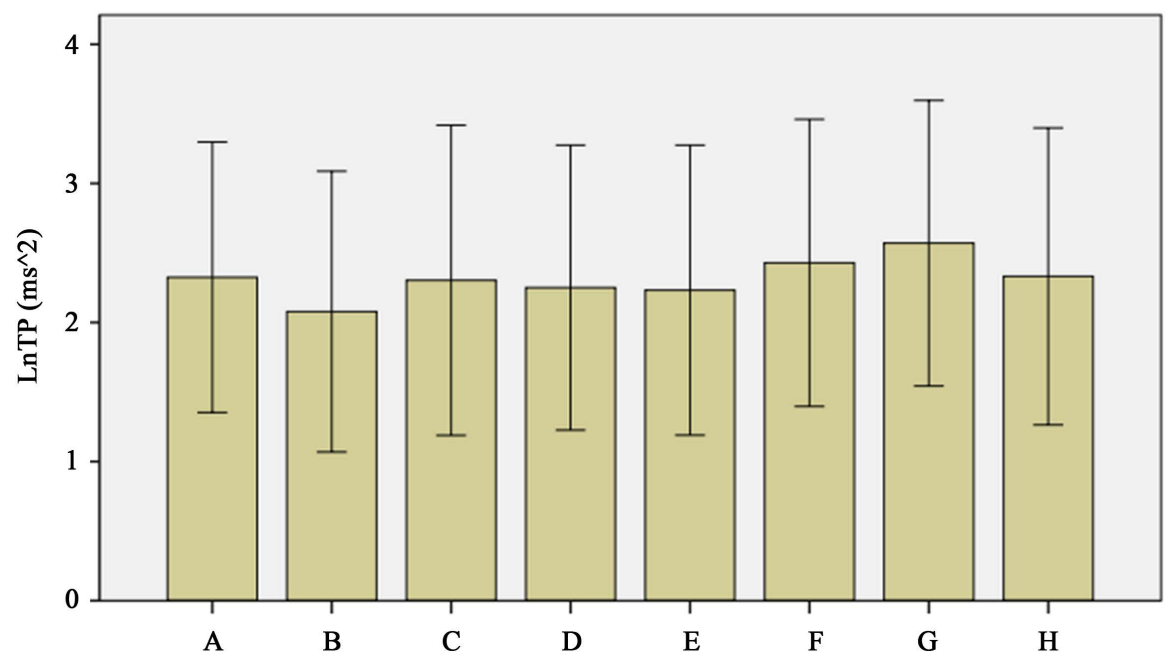

Figure 2. The relationship between LnTP and activity.

Table 1. Subject age (in tens of years) and sex.

\begin{tabular}{cccc}
\hline Age & Man & Female & Total \\
\hline 10 's & 1058 & 9448 & 10,506 \\
20 rs & 1433 & 7621 & 9054 \\
30rs & 1342 & 1856 & 3198 \\
40 's & 1406 & 1404 & 2810 \\
50 rs & 884 & 528 & 1412 \\
Over 60's & 271 & 56 & 327 \\
Total & 6394 & 20,913 & 27,307 \\
\hline
\end{tabular}

Table 2. Data by activity.

\begin{tabular}{cccc}
\hline Action & Man & Female & Total \\
A & 5356 & 13,043 & 18,399 \\
B & 1371 & 3338 & 4709 \\
C & 837 & 2039 & 2876 \\
D & 2641 & 6431 & 9072 \\
E & 5034 & 12,260 & 17,294 \\
F & 12,661 & 30,834 & 43,495 \\
G & 4587 & 11,171 & 15,759 \\
H & 5544 & 13,501 & 19,045 \\
Total & 38,030 & 92,618 & 130,648 \\
\hline
\end{tabular}

A: Work; B: Housework; C: Exercise; D: Movement; E: Meal; F: Leisure; G: Sleep; H: Other. 
Table 3. Multiple comparison results (LnTP and activity).

\begin{tabular}{|c|c|c|c|c|c|c|}
\hline \multicolumn{7}{|c|}{ Multiple Comparisons } \\
\hline \multicolumn{7}{|c|}{ Dependent Variable: LnTP } \\
\hline \multicolumn{7}{|c|}{ Games-Howell } \\
\hline \multirow{2}{*}{ (1) AcN } & \multirow{2}{*}{ (J) $\mathrm{AcN}$} & \multirow{2}{*}{ Mean Difference (1-J) } & \multirow{2}{*}{ Std. Error } & \multirow{2}{*}{ Sig. } & \multicolumn{2}{|c|}{ 95\% Confidence Interval } \\
\hline & & & & & Lower Bound & Upper Bound \\
\hline \multirow{7}{*}{ Work } & Housework & $0.2470^{*}$ & 0.0223 & 0.000 & 0.179 & 0.315 \\
\hline & Exercise & 0.0218 & 0.0301 & 0.996 & -0.069 & 0.113 \\
\hline & Movement & $0.0747^{*}$ & 0.0177 & 0.001 & 0.021 & 0.128 \\
\hline & Meal & $0.0928^{*}$ & 0.0146 & 0.000 & 0.049 & 0.137 \\
\hline & Leisure & $-0.1038^{*}$ & 0.0119 & 0.000 & -0.140 & -0.068 \\
\hline & Sleep & $-0.2452^{*}$ & 0.0149 & 0.000 & -0.290 & -0.200 \\
\hline & Other & -0.0062 & 0.0144 & 1.000 & -0.050 & 0.037 \\
\hline \multirow{7}{*}{ Housework } & Work & $-0.2470^{*}$ & 0.0223 & 0.000 & -0.315 & -0.179 \\
\hline & Exercise & $-0.2252^{*}$ & 0.0348 & 0.000 & -0.331 & -0.120 \\
\hline & Movement & $-0.1723^{*}$ & 0.0249 & 0.000 & -0.248 & -0.097 \\
\hline & Meal & $-0.1542^{*}$ & 0.0228 & 0.000 & -0.223 & -0.085 \\
\hline & Leisure & $-0.3507^{*}$ & 0.0212 & 0.000 & -0.415 & -0.286 \\
\hline & Sleep & $-0.4922^{*}$ & 0.023 & 0.000 & -0.562 & -0.422 \\
\hline & Other & $-0.2532^{*}$ & 0.0227 & 0.000 & -0.322 & -0.184 \\
\hline \multirow{7}{*}{ Exercise } & Work & -0.0218 & 0.0301 & 0.996 & -0.113 & 0.069 \\
\hline & Housework & $0.2252^{*}$ & 0.0348 & 0.000 & 00.12 & 0.331 \\
\hline & Movement & 0.0529 & 0.032 & 0.717 & -0.044 & 0.150 \\
\hline & Meal & 0.0711 & 0.0304 & 0.274 & -0.021 & 0.163 \\
\hline & Leisure & $-0.1255^{*}$ & 0.0292 & 0.000 & -0.214 & -0.037 \\
\hline & Sleep & $-0.2669^{*}$ & 0.0305 & 0.000 & -0.360 & -0.174 \\
\hline & Other & -0.0279 & 0.0303 & 0.984 & -0.120 & 0.064 \\
\hline \multirow{7}{*}{ Movement } & Work & $-0.0747^{*}$ & 0.0177 & 0.001 & -0.128 & -0.021 \\
\hline & Housework & $0.1723^{*}$ & 0.0249 & 0.000 & 0.097 & 0.248 \\
\hline & Exercise & -0.0529 & 0.032 & 0.717 & -0.150 & 0.044 \\
\hline & Meal & 0.0181 & 0.0182 & 0.975 & -0.037 & 0.073 \\
\hline & Leisure & $-0.1784^{*}$ & 0.0162 & 0.000 & -0.227 & -0.129 \\
\hline & Sleep & $-0.3199^{*}$ & 0.0185 & 0.000 & -0.376 & -0.264 \\
\hline & Other & -0.0809 & 0.0181 & 0.000 & -0.136 & -0.026 \\
\hline \multirow{7}{*}{ Meal } & Work & -0.0928 & 0.0146 & 0.000 & -0.137 & -0.049 \\
\hline & Housework & $0.1542^{*}$ & 0.0228 & 0.000 & 0.085 & 0.223 \\
\hline & Exercise & -0.0711 & 0.0304 & 0.274 & -0.163 & 0.021 \\
\hline & Movement & -0.0181 & 0.0182 & 0.975 & -0.073 & 0.037 \\
\hline & Leisure & $-0.1966^{*}$ & 0.0128 & 0.000 & -0.235 & -0.158 \\
\hline & Sleep & $-0.3380^{*}$ & 0.0156 & 0.000 & -0.385 & -0.291 \\
\hline & Other & $-0.0990^{\prime}$ & 0.0151 & 0.000 & -0.145 & -0.053 \\
\hline
\end{tabular}




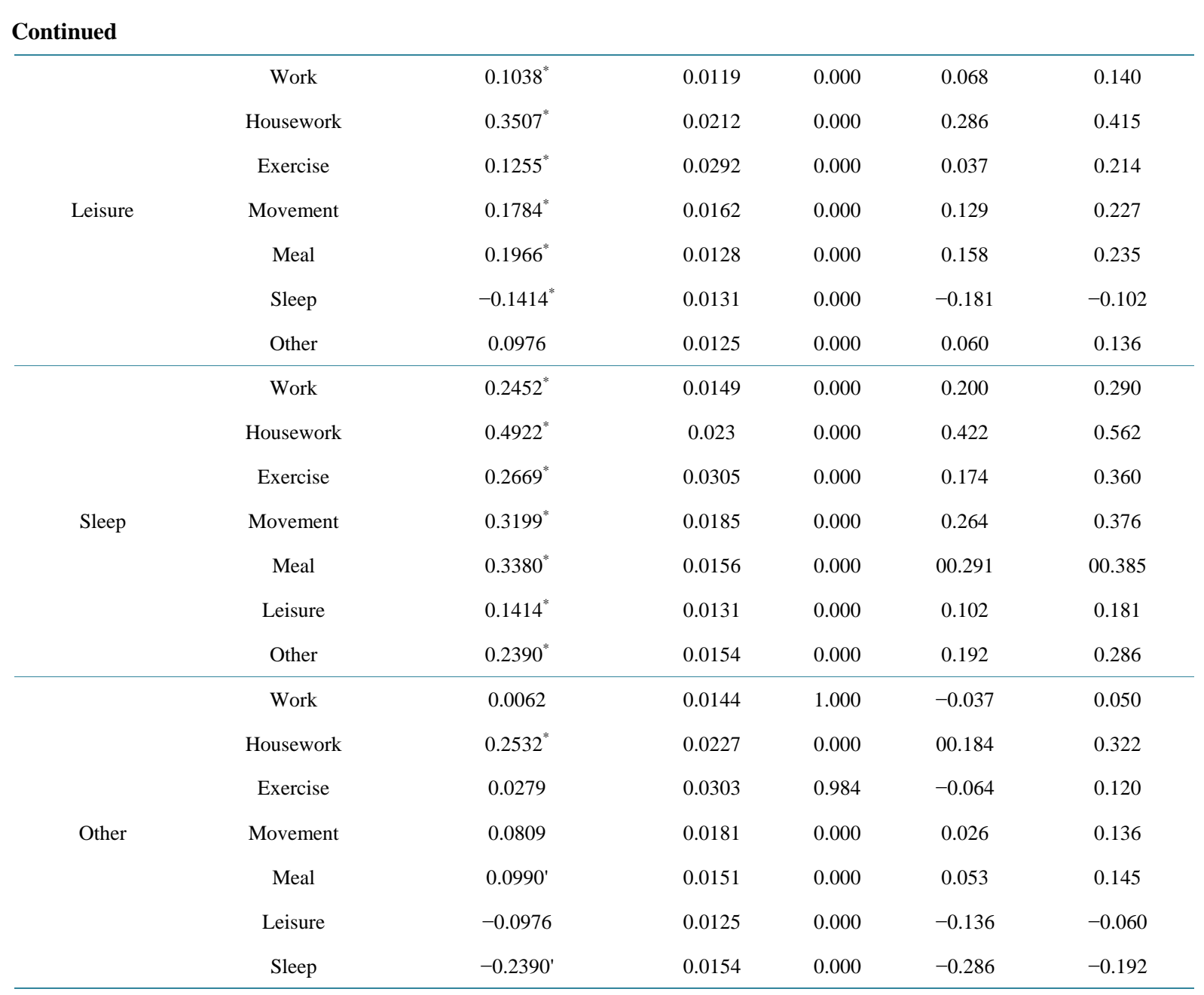

*The mean difference is significant at the 0.05 level.

fective in increasing autonomic nervous system and function. Conversely, total power was found to be low during housework.

\subsection{The Relationship between LF/HF and Activity}

In this section, the relationship between LF/HF (an indicator of sympathetic nervous activity) and region is investigated. It is said that performing logarithmic transformation on LF/HF increases its normality [15], so logarithmic transformation was performed on the LF/HF values (LnLF/HF) for all the measurement data. A GamesHowell multiple comparison procedure was then performed on these values, the results of which are given in Figure 3 and Table 4. Sympathetic nervous activity was found to rise significantly after waking and during work, while during leisure time, it was found that sympathetic nervous activity is inhibited. These trends were also observed when analyzing data separately by sex.

It has been observed in previous research that sympathetic nervous activity rises before and after waking [16], a trend that is consistent with observations made in this study.

It was also observed that during leisure time, sympathetic nervous activity is inhibited and subjects are relaxed.

\subsection{Summary}

As part of the relationship between autonomic nervous system and activity, it was found that during leisure time, sympathetic nervous activity is inhibited, total power is high, and autonomic nervous system is good. It is said 
Table 4. Multiple comparison results (LnLF/HF and activity).

\begin{tabular}{|c|c|c|c|c|c|c|}
\hline \multicolumn{7}{|c|}{ Multiple Comparisons } \\
\hline \multicolumn{7}{|c|}{ Dependent Variable: LnLF.HF } \\
\hline \multicolumn{7}{|c|}{ Games-Howell } \\
\hline \multirow{2}{*}{ (1) AcN } & \multirow{2}{*}{ (J) AcN } & \multirow{2}{*}{ Mean Difference (1-J) } & \multirow{2}{*}{ Std. Error } & \multirow{2}{*}{ Sig. } & \multicolumn{2}{|c|}{ 95\% Confidence Interval } \\
\hline & & & & & Lower Bound & Upper Bound \\
\hline \multirow{7}{*}{ Work } & Housework & $0.1036^{*}$ & 0.0205 & 0.000 & 0.041 & 0.166 \\
\hline & Exercise & 0.0704 & 0.0242 & 00.071 & -0.003 & 0.144 \\
\hline & Movement & 0.0301 & 0.0150 & 0.479 & -0.015 & 0.076 \\
\hline & Meal & 0.0007 & 0.0128 & 1.000 & -0.038 & 0.039 \\
\hline & Leisure & 0.0895 & 0.0108 & 0.000 & 0.057 & 0.122 \\
\hline & Sleep & $-0.0457^{*}$ & 0.0141 & 0.026 & -0.088 & -0.003 \\
\hline & Other & 0.0574 & 0.0128 & 0.000 & 0.019 & 0.096 \\
\hline \multirow{7}{*}{ Housework } & Work & $-0.1036^{*}$ & 0.0205 & 0.000 & -0.166 & -0.041 \\
\hline & Exercise & -0.0332 & 0.0291 & 0.948 & -0.121 & 0.055 \\
\hline & Movement & $-0.0735^{*}$ & 0.0221 & 0.020 & -0.140 & -0.007 \\
\hline & Meal & $-0.1029^{*}$ & 0.0206 & 0.000 & -0.165 & -0.040 \\
\hline & Leisure & -0.0141 & 0.0195 & 0.996 & -0.073 & 0.045 \\
\hline & Sleep & $-0.1493^{*}$ & 0.0215 & 0.000 & -0.214 & -0.084 \\
\hline & Other & -0.0462 & 0.0206 & 0.328 & -0.109 & 0.016 \\
\hline \multirow{7}{*}{ Exercise } & Work & -0.0704 & 0.0242 & 0.071 & -0.144 & 0.003 \\
\hline & Housework & 00.0332 & 0.0291 & 0.948 & -0.055 & 0.121 \\
\hline & Movement & -0.0404 & 0.0255 & 0.762 & -0.118 & 0.037 \\
\hline & Meal & -0.0697 & 0.0243 & 0.080 & -0.143 & 0.004 \\
\hline & Leisure & 0.0191 & 0.0233 & 0.992 & -0.052 & 0.090 \\
\hline & Sleep & $-0.1161^{*}$ & 0.0250 & 0.000 & -0.192 & -0.040 \\
\hline & Other & -0.0130 & 0.0243 & 0.999 & -0.087 & 00.061 \\
\hline \multirow{7}{*}{ Movement } & Work & -0.0301 & 0.0150 & 0.479 & -0.076 & 0.015 \\
\hline & Housework & $0.0735^{\prime}$ & 0.0221 & 0.020 & 0.007 & 0.140 \\
\hline & Exercise & 0.0404 & 0.0255 & 0.762 & -0.037 & 0.118 \\
\hline & Meal & -0.0293 & 0.0152 & 0.528 & -0.075 & 0.017 \\
\hline & Leisure & $0.0594^{*}$ & 0.0136 & 0.000 & 0.018 & 0.101 \\
\hline & Sleep & $-0.0757^{*}$ & 0.0163 & 0.000 & -0.125 & -0.026 \\
\hline & Other & 0.0273 & 0.0152 & 0.619 & -0.019 & 0.073 \\
\hline \multirow{7}{*}{ Meal } & Work & -0.0007 & 0.0128 & 1.000 & -0.039 & 0.038 \\
\hline & Housework & 0.10290 & 0.0206 & 0.000 & 0.040 & 0.165 \\
\hline & Exercise & 0.0697 & 0.0243 & 0.080 & -0.004 & 0.143 \\
\hline & Movement & 0.0293 & 0.0152 & 0.528 & -0.017 & 0.075 \\
\hline & Leisure & 0.0887 & 0.0111 & 0.000 & 0.055 & 0.122 \\
\hline & Sleep & $-0.0464^{\prime}$ & 0.0143 & 0.025 & -0.090 & -0.003 \\
\hline & Other & 0.0567 & 0.0130 & 0.000 & 0.017 & 0.096 \\
\hline
\end{tabular}




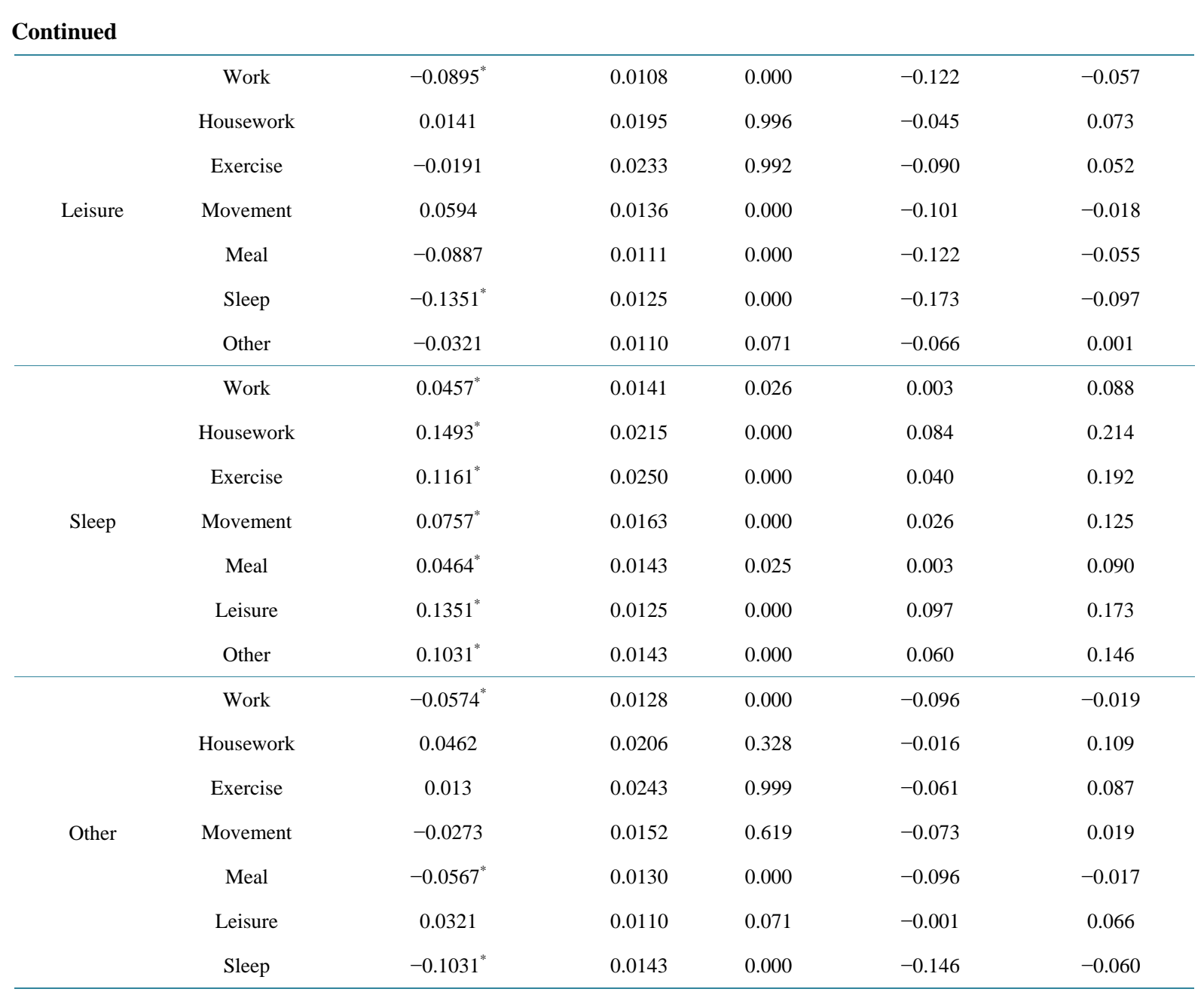

*The mean difference is significant at the 0.05 level.

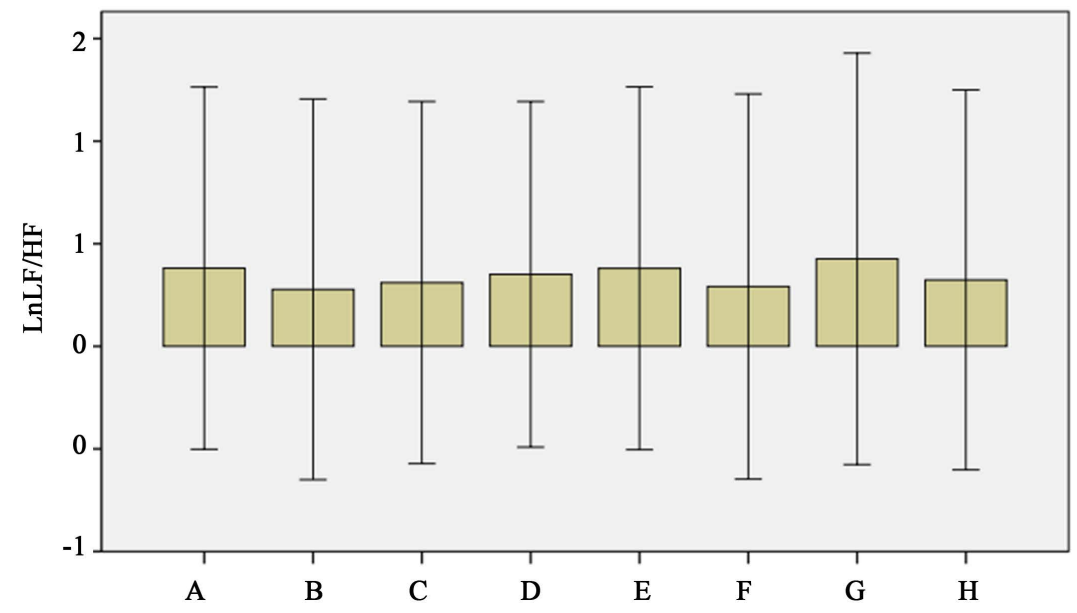

Figure 3. The relationship between LnLF/HF and activity.

that in our lives as members of society, it is important to set aside a moderate amount of time for leisure. The current study managed to demonstrate this usefulness (using a large amount of data) statistically, a valuable contribution to society. 
It was also found that during work, sympathetic nervous activity is high and subjects are in a state of tension. In addition to its other applications, this data could serve useful to companies in their promotion of healthy business activities (taking into consideration employee care, etc.).

Additionally, it was found that during housework, sympathetic function is inhibited, but total power is lower. The study results reveal statistically (using a large amount of data) that while housework is not as tense as work, it is nonetheless a physically fatiguing activity.

Thus, this data could contribute to the increased societal recognition of the difficulties of housework, and the advancement in social status of stay-at-home wives (and husbands).

\section{The Relationship between Autonomic Nervous System and Day of the Week}

In this section, a relationship (under everyday circumstances) between autonomic nervous system and activity is shown. In the research conducted up to this point, there have been few reports analyzing trends (based on a large amount of data) in autonomic nervous system (under everyday circumstances) for different days of the week.

\subsection{The Relationship between Total Power and Day of the Week}

In this section, the relationship between total power and day of the week is investigated. Information on the measurement data used in the study's analysis is given in Table 5 .

Data was divided into seven groups based on day of the week, and the differences between groups were analyzed by performing logarithmic transformation on the TP values (LnTP) for all the measurement data, and then performing a Games-Howell multiple comparison procedure. The results are given in Figure 4 and Table 6.

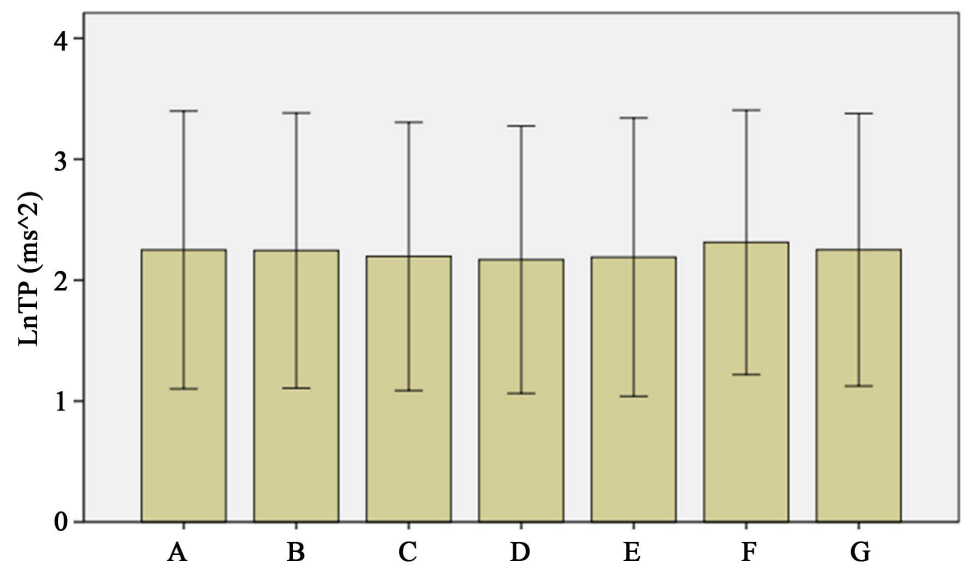

Figure 4. The relationship between LnTP and day of the week.

Table 5. Data by day of the week.

\begin{tabular}{cccc}
\hline Day of week & Man & Female & Total \\
A & 5787 & 14,093 & 13,006 \\
B & 5340 & 11,436 & 18,880 \\
C & 4696 & 11,719 & 196,132 \\
D & 4812 & 11,834 & 16,531 \\
E & 4859 & 16,000 & 16,693 \\
F & 6570 & 14,530 & 22,569 \\
G & 5966 & 92,618 & 130,648
\end{tabular}

A: Monday; B: Tuesday; C: Wednesday; D: Thursday; E: Friday; F: Saturday; G: Sunday. 
Table 6. Multiple comparison results (LnTP and day of the week).

\begin{tabular}{|c|c|c|c|c|c|c|}
\hline \multicolumn{7}{|c|}{ Multiple Comparisons } \\
\hline \multicolumn{7}{|c|}{ Dependent Variable: LnTP } \\
\hline \multicolumn{7}{|c|}{ Games-Howell } \\
\hline \multirow{2}{*}{ (1) WDN } & \multirow{2}{*}{ (J) WDN } & \multirow{2}{*}{ Mean Difference (1-J) } & \multirow{2}{*}{ Std. Error } & \multirow{2}{*}{ Sig. } & \multicolumn{2}{|c|}{ 95\% Confidence Interval } \\
\hline & & & & & Lower Bound & Upper Bound \\
\hline \multirow{6}{*}{ Monday } & Tuesday & 0.0052 & 0.0137 & 1.000 & -0.035 & 0.046 \\
\hline & Wednesday & $0.0539^{*}$ & 0.014 & 0.002 & 0.013 & 0.095 \\
\hline & Thursday & $0.0804^{*}$ & 0.0139 & 0.000 & 0.039 & 0.121 \\
\hline & Friday & $0.0600^{*}$ & 0.0141 & 0.000 & 0.018 & 0.102 \\
\hline & Saturday & $-0.0624^{\prime}$ & 0.0128 & 0.000 & -0.100 & -0.025 \\
\hline & Sunday & -0.0014 & 0.0133 & 1.000 & -0.040 & 0.038 \\
\hline \multirow{6}{*}{ Tuesday } & Monday & -0.0052 & 0.0137 & 1.000 & -0.046 & 0.035 \\
\hline & Wednesday & $0.0487^{*}$ & 0.0142 & 0.011 & 0.007 & 0.091 \\
\hline & Thursday & $0.0752^{*}$ & 0.0141 & 0.000 & 0.034 & 0.117 \\
\hline & Friday & $0.0548^{*}$ & 0.0143 & 0.003 & 0.013 & 0.097 \\
\hline & Saturday & 0.0676 & 0.0130 & 0.000 & -0.106 & -0.029 \\
\hline & Sunday & -0.0066 & 0.0135 & 0.999 & -0.046 & 0.033 \\
\hline \multirow{6}{*}{ Wednesday } & Monday & $-0.0539^{*}$ & 0.014 & 0.002 & -0.095 & -0.013 \\
\hline & Tuesday & $-0.0487^{*}$ & 0.0142 & 0.011 & -0.091 & -0.007 \\
\hline & Thursday & 0.0265 & 0.0143 & 0.517 & -0.016 & 0.069 \\
\hline & Friday & 0.0061 & 0.0146 & 1.000 & -0.037 & 0.049 \\
\hline & Saturday & $-0.1163^{*}$ & 0.0133 & 0.000 & -0.156 & -0.077 \\
\hline & Sunday & $-0.0553^{*}$ & 0.0138 & 0.001 & -0.096 & -0.015 \\
\hline \multirow{6}{*}{ Thursday } & Monday & -0.0804 & 0.0139 & 0.000 & -0.121 & -0.039 \\
\hline & Tuesday & $-0.0752^{*}$ & 0.0141 & 0.000 & -0.117 & -0.034 \\
\hline & Wednesday & -0.0265 & 0.0143 & 0.517 & -0.069 & 0.016 \\
\hline & Friday & -0.0204 & 0.0145 & 0.799 & -0.063 & 0.022 \\
\hline & Saturday & $-0.1428^{*}$ & 0.0132 & 0.000 & -0.182 & -0.104 \\
\hline & Sunday & $-0.0818^{*}$ & 0.0136 & 0.000 & -0.122 & -0.042 \\
\hline \multirow{6}{*}{ Friday } & Monday & $-0.0600^{*}$ & 0.0141 & 0.000 & -0.102 & -0.018 \\
\hline & Tuesday & $-0.0548^{*}$ & 0.0143 & 0.003 & -0.097 & -0.013 \\
\hline & Wednesday & -0.0061 & 0.0146 & 1.000 & -0.049 & 0.037 \\
\hline & Thursday & 0.0204 & 0.0145 & 0.799 & -0.022 & 0.063 \\
\hline & Saturday & $-0.1224^{*}$ & 0.0135 & 0.000 & -0.162 & -0.083 \\
\hline & Sunday & $-0.0614^{*}$ & 0.0139 & 0.000 & -0.102 & -0.020 \\
\hline
\end{tabular}




\begin{tabular}{|c|c|c|c|c|c|c|}
\hline \multirow{6}{*}{ Saturday } & Monday & $0.0624^{*}$ & 0.0128 & 0.000 & 0.025 & 0.100 \\
\hline & Tuesday & $0.0676^{*}$ & 0.013 & 0.000 & 0.029 & 0.106 \\
\hline & Wednesday & $0.1163^{*}$ & 0.0133 & 0.000 & 0.077 & 0.156 \\
\hline & Thursday & $0.1428^{*}$ & 0.0132 & 0.000 & 0.104 & 0.182 \\
\hline & Friday & $0.1224^{*}$ & 0.0135 & 0.000 & 0.083 & 0.162 \\
\hline & Sunday & $0.0610^{*}$ & 0.0125 & 0.000 & 0.024 & 0.098 \\
\hline \multirow{6}{*}{ Sunday } & Monday & 0.0014 & 0.0133 & 1.000 & -0.038 & 0.040 \\
\hline & Tuesday & 0.0066 & 0.0135 & 0.999 & -0.033 & 0.046 \\
\hline & Wednesday & $0.0553^{*}$ & 0.0138 & 0.001 & 0.015 & 0.096 \\
\hline & Thursday & $0.0818^{*}$ & 0.0136 & 0.000 & 0.042 & 0.122 \\
\hline & Friday & $0.0614^{*}$ & 0.0139 & 0.000 & 0.020 & 0.102 \\
\hline & Saturday & $-0.0610^{*}$ & 0.0125 & 0.000 & -0.098 & -0.024 \\
\hline
\end{tabular}

*The mean difference is significant at the 0.05 level.

Total power was found to significantly decrease from the middle through the latter part of the week (namely, Wednesday, Thursday, and Friday), while it significantly increases on Saturday. These trends were also observed when analyzing data separately by sex.

While there is believed to be some dispersion based on region and workplace, according to information reported by the Ministry of Health, Labour, and Welfare on industrial accident occurrence by day of the week [17], accumulating fatigue, decreasing concentration, and other factors contribute to a high incidence of industrial accidents around Thursday (with the weekend approaching). In the report, the work week starts on Monday.

Most people have likely experienced increasing fatigue from the middle through the latter part of the week, a trend that is consistent with the current study's finding that total power decreases during the same period of the week.

\subsection{The Relationship between LF/HF and Day of the Week}

In this section, the relationship between LF/HF (an indicator of sympathetic nervous activity) and day of the week is investigated. Logarithmic transformation was performed on the LF/HF values (LnLF/HF) for all the measurement data, and then a Games-Howell multiple comparison procedure was performed. The results are given in Figure 5 and Table 7. Sympathetic nervous activity was found to decrease significantly on Saturday, a trend that was also observed when analyzing data separately by sex. As mentioned previously, total power was found to be high on Saturday. It can be said that, compared to other days of the week, autonomic nervous system is extremely good on Saturday.

This may be influenced by the cycle of the days of the week: the sympathetic nervous activity of many people increases during weekdays as they are kept busy with work, housework, and other duties, and this increase is seen again on Sunday as peoples' tension and emotions rise in anticipation of the coming week.

\subsection{Summary}

As part of the relationship between autonomic nervous system and day of the week, it was found that from the latter half of the week, total power decreases and subjects fatigue slightly. This data should prove extremely beneficial to companies.

For instance, by changing "no overtime day" from Wednesday (as it is usually scheduled) to Thursday, company productivity may increase.

What's more, this study (using a large amount of data) has managed to give statistical proof to what is commonly referred to in Japan as "Sazae-san Syndrome", a phenomenon in which people become quite depressed on Sunday as they think about work or school starting up again the following day. This will likely prove very valu- 
Table 7. Multiple comparison results (Lnlf/Hf and day of the week).

\begin{tabular}{|c|c|c|c|c|c|c|}
\hline \multicolumn{7}{|c|}{ Multiple Comparisons } \\
\hline \multicolumn{7}{|c|}{ Dependent Variable: LnLF.HF } \\
\hline \multicolumn{7}{|c|}{ Games-Howell } \\
\hline \multirow{2}{*}{ (1) WDN } & \multirow{2}{*}{ (J) WDN } & \multirow{2}{*}{ Mean Difference (1-J) } & \multirow{2}{*}{ Std. Error } & \multirow{2}{*}{ Sig. } & \multicolumn{2}{|c|}{ 95\% Confidence Interval } \\
\hline & & & & & Lower Bound & Upper Bound \\
\hline \multirow{6}{*}{ Monday } & Tuesday & -0.0045 & 0.0119 & 1.000 & -0.040 & 0.031 \\
\hline & Wednesday & -0.0005 & 0.0123 & 1.000 & -0.037 & 0.036 \\
\hline & Thursday & 0.0047 & 0.0122 & 1.000 & -0.031 & 0.041 \\
\hline & Friday & -0.0052 & 0.0122 & 1.000 & -0.041 & 0.031 \\
\hline & Saturday & 0.0307 & 0.0113 & 0.094 & -0.003 & 0.064 \\
\hline & Sunday & 0.0152 & 0.0117 & 0.852 & -0.019 & 0.050 \\
\hline \multirow{6}{*}{ Tuesday } & Monday & 0.0045 & 0.0119 & 1.000 & -0.031 & 0.040 \\
\hline & Wednesday & 0.0040 & 0.0125 & 1.000 & -0.033 & 0.041 \\
\hline & Thursday & 0.0091 & 0.0125 & 0.991 & -0.028 & 0.046 \\
\hline & Friday & -0.0007 & 0.0125 & 1.000 & -0.038 & 0.036 \\
\hline & Saturday & $0.0352^{*}$ & 0.0116 & 0.039 & 0.001 & 0.069 \\
\hline & Sunday & 0.0196 & 0.0119 & 0.653 & -0.016 & 0.055 \\
\hline \multirow{6}{*}{ Wednesday } & Monday & 0.0005 & 0.0123 & 1.000 & -0.036 & 0.037 \\
\hline & Tuesday & -0.0040 & 0.0125 & 1.000 & -0.041 & 0.033 \\
\hline & Thursday & 0.0051 & 0.0129 & 1.000 & -0.033 & 0.043 \\
\hline & Friday & -0.0048 & 0.0129 & 1.000 & -0.043 & 0.033 \\
\hline & Saturday & 0.0311 & 0.0120 & 0.126 & -0.004 & 0.066 \\
\hline & Sunday & 0.0156 & 0.0123 & 0.867 & -0.021 & 0.052 \\
\hline \multirow{6}{*}{ Thursday } & Monday & -0.0047 & 0.0122 & 1.000 & -0.041 & 00.031 \\
\hline & Tuesday & 0.0091 & 0.0125 & 0.991 & -0.046 & 0.028 \\
\hline & Wednesday & -0.0051 & 0.0129 & 1.000 & -0.043 & 0.033 \\
\hline & Friday & -0.0099 & 0.0128 & 0.988 & -0.048 & 0.028 \\
\hline & Saturday & 0.0260 & 0.0119 & 0.304 & -0.009 & 0.061 \\
\hline & Sunday & 0.0105 & 0.0123 & 0.979 & -0.026 & 0.047 \\
\hline \multirow{6}{*}{ Friday } & Monday & 0.0052 & 0.0122 & 1.000 & -0.031 & 00.041 \\
\hline & Tuesday & 0.0007 & 0.0125 & 1.000 & -0.036 & 0.038 \\
\hline & Wednesday & 0.0048 & 0.0129 & 1.000 & -0.033 & 0.043 \\
\hline & Thursday & 0.0099 & 0.0128 & 0.988 & -0.028 & 0.048 \\
\hline & Saturday & $0.0359^{*}$ & 0.0120 & 0.043 & 0.001 & 0.071 \\
\hline & Sunday & 0.0204 & 0.0123 & 0.645 & -0.016 & 00.057 \\
\hline
\end{tabular}




\begin{tabular}{ccccccc} 
Continued & & & & & \\
\hline & Monday & -0.0307 & 0.0113 & 0.094 & -0.064 & 0.003 \\
Tuesday & $-0.0352^{*}$ & 0.0116 & 0.039 & -0.069 & -0.001 \\
Saturday & -0.0311 & 0.0120 & 00.126 & -0.066 & 0.004 \\
& Wednesday & -0.0260 & 0.0119 & 0.304 & -0.061 & -0.001 \\
& Thursday & $-0.0359^{*}$ & 0.0120 & 0.043 & -0.071 & 0.018 \\
\hline \multirow{3}{*}{ Friday } & -0.0155 & 0.0114 & 0.820 & -0.049 & 0.019 \\
& Sunday & -0.0152 & 0.0117 & 0.852 & -0.050 & 0.016 \\
& Monday & -0.0196 & 0.0119 & 0.653 & -0.055 & 00.021 \\
& Tuesday & -0.0156 & 0.0123 & 0.867 & -0.052 & 0.026 \\
& Wednesday & -0.0105 & 0.0123 & 0.979 & -0.047 & -0.057 \\
\hline & Thursday & -0.0204 & 0.0123 & 0.645 & -0.018 & 0.016 \\
\hline
\end{tabular}

* The mean difference is significant at the 0.05 level.

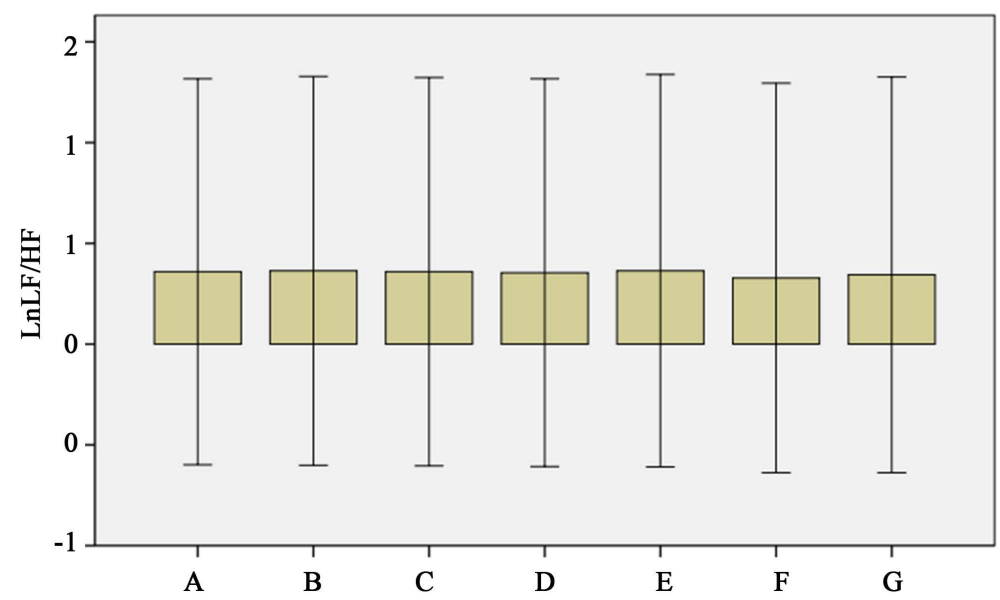

Figure 5. The relationship between $\mathrm{LnLF} / \mathrm{HF}$ and day of the week.

able to society. By spreading awareness of such weekly cycles in autonomic nervous system, this study's data could serve useful in the adjustment of work/housework load across the week, as well as other facets of health preservation and promotion.

\section{The Relationship between Autonomic Nervous System and Region}

In this section, a relationship (under everyday circumstances) between autonomic nervous system and region is shown. In the research conducted up to this point, there have been few reports analyzing regional trends (based on a large amount of data) in autonomic nervous system under everyday circumstances.

\subsection{The Relationship between Total Power and Regions}

In this section, the relationship between total power and region is investigated. Information on the study subjects and the measurement data used in the study's analysis is given in Table 8 and Table 9. Data was divided into eight groups based on prefecture, and the differences between groups were analyzed by performing logarithmic transformation on the TP values (LnTP) for all the measurement data, and then performing a Games-Howell multiple comparison procedure. The results are given in Figure 6 and Table 10. The total power of the Kanto 
Table 8. Region of residence for subjects.

\begin{tabular}{cccc}
\hline Area & Man & Female & Total \\
A & 459 & 1833 & 2292 \\
B & 3276 & 7396 & 10,672 \\
C & 272 & 1040 & 1312 \\
D & 600 & 2345 & 2945 \\
E & 983 & 4066 & 5049 \\
F & 213 & 1128 & 1341 \\
G & 101 & 580 & 681 \\
H & 490 & 2525 & 3015 \\
Total & 6394 & 20,913 & 27,307 \\
\hline
\end{tabular}

A: Hokkaido and Tohoku; B: Kanto; C: Koshinetsu; D: Chubu; E: Kinki; F: Chugoku; G: Shikoku; H: Kyushu and Okinawa.

Table 9. Data by region.

\begin{tabular}{cccc}
\hline Area & Man & Female & Total \\
A & 2942 & 7983 & 10,925 \\
B & 20,738 & 35,881 & 56,619 \\
C & 1789 & 4563 & 6352 \\
D & 3462 & 10,778 & 14,240 \\
E & 5058 & 15,955 & 21,013 \\
F & 1276 & 4797 & 6073 \\
G & 525 & 2341 & 2866 \\
H & 2240 & 10,320 & 12,560 \\
Total & 38,030 & 92,618 & 130,648 \\
\hline
\end{tabular}

Table 10. Multiple comparison results (LnTP and region).

\begin{tabular}{|c|c|c|c|c|c|c|}
\hline \multicolumn{7}{|c|}{ Multiple Comparisons } \\
\hline \multicolumn{7}{|c|}{ Dependent Variable: LnTP } \\
\hline \multicolumn{7}{|c|}{ Games-Howell } \\
\hline \multirow{2}{*}{ (1) $\mathrm{AN}$} & \multirow{2}{*}{ (J) $\mathrm{AN}$} & \multirow{2}{*}{$\begin{array}{c}\text { Mean } \\
\text { Difference } \\
(1-\mathrm{J})\end{array}$} & \multirow{2}{*}{ Std. Error } & \multirow{2}{*}{ Sig. } & \multicolumn{2}{|c|}{ 95\% Confidence Interval } \\
\hline & & & & & Lower Bound & Upper Bound \\
\hline \multirow{7}{*}{ Hokkaido and Tohoku } & Kanto & $0.1369^{*}$ & 0.0108 & 0.000 & 0.104 & 0.170 \\
\hline & Koshinetsu & -0.0092 & 0.0163 & 0.999 & -0.059 & 0.040 \\
\hline & Chubu & 0.0003 & 0.0131 & 1.000 & -0.039 & 0.040 \\
\hline & Kinki & 0.0242 & 0.0122 & 0.494 & -0.013 & 00.061 \\
\hline & Chugoku & 0.0420 & 0.0169 & 0.203 & -0.009 & 0.093 \\
\hline & Shikoku & $-0.0922^{*}$ & 0.0210 & 0.000 & -0.156 & -0.028 \\
\hline & Kyushu and Okinawa & 0.0114 & 0.0135 & 0.991 & -0.030 & 0.052 \\
\hline \multirow{7}{*}{ Kanto } & Hokkaido and Tohoku & $-0.1369^{*}$ & 0.0108 & 0.000 & -0.170 & -0.104 \\
\hline & Koshinetsu & $-0.1461^{*}$ & 0.0137 & 0.000 & -0.188 & -0.104 \\
\hline & Chubu & $-0.1366^{*}$ & 0.0096 & 0.000 & -0.166 & -0.107 \\
\hline & Kinki & $-0.1127^{*}$ & 0.0085 & 0.000 & -0.138 & -0.087 \\
\hline & Chugoku & $-0.0949^{*}$ & 0.0144 & 0.000 & -0.139 & -0.051 \\
\hline & Shikoku & $-0.2291^{*}$ & 0.0191 & 0.000 & -0.287 & -0.171 \\
\hline & Kyushu and Okinawa & $-0.1255^{*}$ & 0.0102 & 0.000 & -0.156 & -0.095 \\
\hline
\end{tabular}




\section{Continued}

\begin{tabular}{|c|c|c|c|c|c|c|}
\hline \multirow{7}{*}{ Koshinetsu } & Hokkaido and Tohoku & 0.0092 & 0.0163 & 0.999 & -0.040 & 0.059 \\
\hline & Kanto & $0.1461^{*}$ & 0.0137 & 0.000 & 0.104 & 0.188 \\
\hline & Chubu & 0.0094 & 0.0156 & 0.999 & -0.038 & 00.057 \\
\hline & Kinki & 0.0334 & 0.0149 & 0.323 & -0.012 & 0.078 \\
\hline & Chugoku & 0.0511 & 0.0189 & 0.121 & -0.006 & 0.108 \\
\hline & Shikoku & $-0.0831^{*}$ & 0.0226 & 0.006 & -0.152 & -0.014 \\
\hline & Kyushu and Okinawa & 0.0206 & 0.0159 & 0.902 & -0.028 & 0.069 \\
\hline \multirow{7}{*}{ Chubu } & Hokkaido and Tohoku & -0.0003 & 0.0131 & 1.000 & -0.040 & 0.039 \\
\hline & Kanto & $0.1366^{*}$ & 0.0096 & 0.000 & 0.107 & 0.166 \\
\hline & Koshinetsu & -0.0094 & 0.0156 & 0.999 & -0.057 & 0.038 \\
\hline & Kinki & 0.0240 & 0.0112 & 0.388 & -0.010 & 0.058 \\
\hline & Chugoku & 0.0417 & 0.0162 & 00.163 & -0.007 & 0.091 \\
\hline & Shikoku & 0.0925 & 0.0204 & 0.000 & -0.154 & -0.031 \\
\hline & Kyushu and Okinawa & 0.0111 & 0.0126 & 0.987 & -0.027 & 0.049 \\
\hline \multirow{7}{*}{ Kinki } & Hokkaido and Tohoku & -0.0242 & 0.0122 & 0.494 & -0.061 & 0.013 \\
\hline & Kanto & $0.1127^{*}$ & 0.0085 & 0.000 & 0.087 & 0.138 \\
\hline & Koshinetsu & -0.0334 & 0.0149 & 0.323 & -0.078 & 0.012 \\
\hline & Chubu & -0.0240 & 0.0112 & 0.388 & -0.058 & 0.010 \\
\hline & Chugoku & 0.0177 & 0.0155 & 0.947 & -0.029 & 0.065 \\
\hline & Shikoku & $-0.1164^{*}$ & 0.0199 & 0.000 & -0.177 & -0.056 \\
\hline & Kyushu and Okinawa & 0.0128 & 0.0117 & 0.958 & -0.048 & 0.023 \\
\hline \multirow{7}{*}{ Chugoku } & Hokkaido and Tohoku & -0.0420 & 0.0169 & 0.203 & -0.093 & 0.009 \\
\hline & Kanto & $0.0949^{*}$ & 0.0144 & 0.000 & 00.051 & 0.139 \\
\hline & Koshinetsu & -0.0511 & 0.0189 & 0.121 & -0.108 & 0.006 \\
\hline & Chubu & -0.0417 & 0.0162 & 00.163 & -0.091 & 0.007 \\
\hline & Kinki & -0.0177 & 0.0155 & 0.947 & -0.065 & 0.029 \\
\hline & Shikoku & $-0.1342^{*}$ & 0.0231 & 0.000 & -0.204 & -0.064 \\
\hline & Kyushu and Okinawa & -0.0306 & 0.0165 & 0.585 & -0.081 & 0.020 \\
\hline \multirow{7}{*}{ Shikoku } & Hokkaido and Tohoku & $0.0922^{*}$ & 0.0210 & 0.000 & 0.028 & 0.156 \\
\hline & Kanto & $0.2291^{*}$ & 0.0191 & 0.000 & 0.171 & 0.287 \\
\hline & Koshinetsu & $0.0831^{*}$ & 0.0226 & 0.006 & 0.014 & 0.152 \\
\hline & Chubu & 0.0925 . & 0.0204 & 0.000 & 0.031 & 0.154 \\
\hline & Kinki & $0.1164^{*}$ & 0.0199 & 0.000 & 0.056 & 0.177 \\
\hline & Chugoku & $0.1342^{*}$ & 0.0231 & 0.000 & 0.064 & 0.204 \\
\hline & Kyushu and Okinawa & $0.1036^{*}$ & 0.0207 & 0.000 & 0.041 & 0.166 \\
\hline \multirow{7}{*}{ Kyushu and Okinawa } & Hokkaido and Tohoku & -0.0114 & 0.0135 & 0.991 & -0.052 & 0.030 \\
\hline & Kanto & $0.1255^{*}$ & 0.0102 & 0.000 & 0.095 & 0.156 \\
\hline & Koshinetsu & -0.0206 & 0.0159 & 0.902 & -0.069 & 0.028 \\
\hline & Chubu & -0.0111 & 0.0126 & 0.987 & -0.049 & 0.027 \\
\hline & Kinki & 0.0128 & 0.0117 & 0.958 & -0.023 & 0.048 \\
\hline & Chugoku & 0.0306 & 0.0165 & 0.585 & -0.020 & 0.081 \\
\hline & Shikoku & $-0.1036^{*}$ & 0.0207 & 0.000 & -0.166 & -0.041 \\
\hline
\end{tabular}

*The mean difference is significant at the 0.05 level. 
region was found to be significantly lower than in other regions, a trend that was also observed when analyzing data separately by sex.

In general, the incidence of autonomic neuropathy is said to be higher in the capital (with its higher stress levels) than in the provinces. This may be correlated with the results of this study.

\subsection{The Relationship between LF/HF and Region}

In this section, the relationship between LF/HF and region is investigated. Logarithmic transformation was performed on the LF/HF values (LnLF/HF) for all the measurement data, and then a Games-Howell multiple comparison procedure was performed. The results are given in Figure 7 and Table 11. No significant difference in LF/HF was observed between regions.

\subsection{Summary}

As part of the relationship between autonomic nervous system and region, it was found that the capital has a lower total power than the provinces, as well as more people who are slightly fatigued. Centralization of Japan's capital, resources, and activities in Tokyo continues to this day, but perhaps pointing out (as this study does) that people living in the provinces have high total power and energy will lead to the provinces' revitalization.

\section{Conclusions}

This study used a large amount of autonomic nervous system data (approximately 100,000 entries) to investigate the relationship between autonomic nervous system and activity, day of the week, and region. Data were meas-

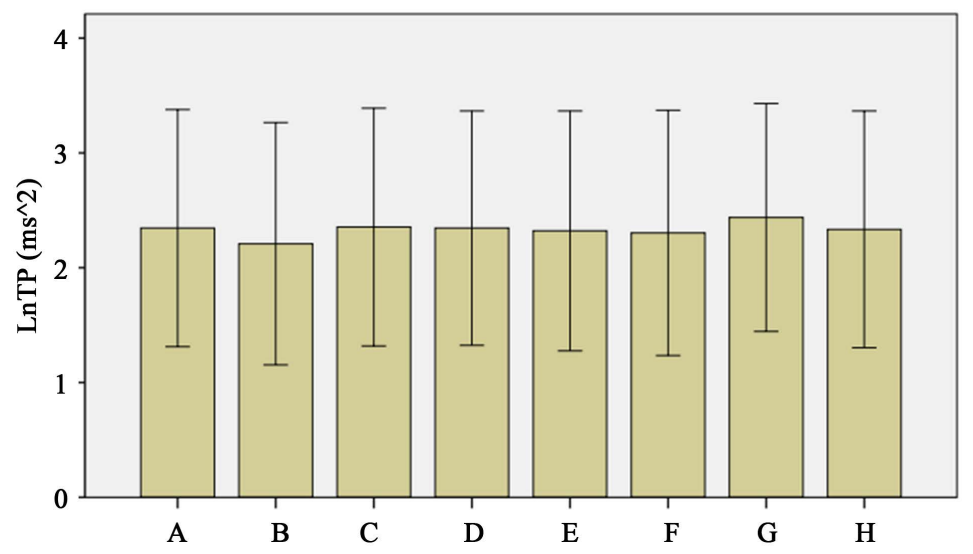

Figure 6. The relationship between LnTP and region.

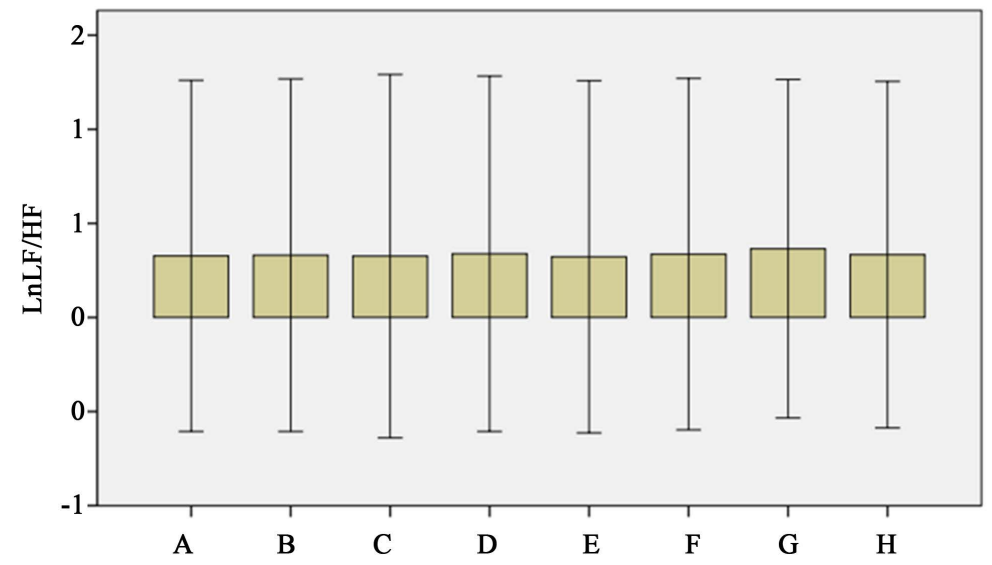

Figure 7. The relationship between $\mathrm{LnLF} / \mathrm{HF}$ and region. 
Table 11. Multiple comparison results (LnLF/HF and region).

\begin{tabular}{|c|c|c|c|c|c|c|}
\hline \multicolumn{7}{|c|}{ Multiple Comparisons } \\
\hline \multicolumn{7}{|c|}{ Dependent Variable: LnLF.HF } \\
\hline \multicolumn{7}{|c|}{ Games-Howell } \\
\hline \multirow{2}{*}{ (1) AN } & \multirow{2}{*}{ (J) AN } & \multirow{2}{*}{$\begin{array}{c}\text { Mean Difference } \\
(1-\mathrm{J})\end{array}$} & \multirow{2}{*}{ Std. Error } & \multirow{2}{*}{ Sig. } & \multicolumn{2}{|c|}{ 95\% Confidence Interval } \\
\hline & & & & & Lower Bound & Upper Bound \\
\hline \multirow{7}{*}{ Hokkaido and Tohoku } & Kanto & -0.0034 & 0.0098 & 10.000 & -0.033 & 0.026 \\
\hline & Koshinetsu & 0.0014 & 0.0150 & 10.000 & -0.044 & 0.047 \\
\hline & Chubu & -0.0108 & 0.0119 & 0.986 & -0.047 & 0.025 \\
\hline & KinKi & 0.0050 & 0.011 & 1.000 & -0.028 & 0.038 \\
\hline & Chugoku & -0.0096 & 0.0149 & 0.998 & -0.055 & 0.036 \\
\hline & Shikoku & 0.0377 & 0.0190 & 0.493 & -0.095 & 0.020 \\
\hline & Kyushu and Okinawa & 0.0063 & 0.0121 & 1.000 & -0.043 & 0.030 \\
\hline \multirow{7}{*}{ Kanto } & Hokkaido and Tohoku & 0.0034 & 0.0098 & 1.000 & -0.026 & 0.033 \\
\hline & Koshinetsu & 0.0048 & 0.0127 & 10.000 & -0.034 & 0.043 \\
\hline & Chubu & 0.0074 & 0.0088 & 0.991 & -0.034 & 0.019 \\
\hline & Kinki & 0.0084 & 0.0076 & 0.955 & -0.015 & 0.031 \\
\hline & Chugoku & -0.0062 & 0.0126 & 1.000 & -0.044 & 0.032 \\
\hline & Shikoku & 0.0344 & 0.0173 & 0.488 & -0.087 & 0.018 \\
\hline & Kyushu and Okinawa & 0.0029 & 0.0091 & 1.000 & -0.031 & 0.025 \\
\hline \multirow{7}{*}{ Koshinetsu } & Hokkaido and Tohoku & -0.0014 & 0.0150 & 1.000 & -0.047 & 0.044 \\
\hline & Kanto & -0.0048 & 0.0127 & 1.000 & -0.043 & 0.034 \\
\hline & Chubu & -0.0122 & 0.0145 & 0.991 & -0.056 & 0.032 \\
\hline & Kinki & 0.0036 & 0.0137 & 1.000 & -0.038 & 0.045 \\
\hline & Chugoku & -0.0111 & 0.0170 & 0.998 & -0.063 & 0.041 \\
\hline & Shikoku & -0.0392 & 0.0207 & 0.557 & -0.102 & 0.024 \\
\hline & Kyushu and Okinawa & 0.0077 & 0.0146 & 1.000 & -0.052 & 0.037 \\
\hline \multirow{7}{*}{ Chubu } & Hokkaido and Tohoku & 0.0108 & 0.0119 & 0.986 & -0.025 & 0.047 \\
\hline & Kanto & 0.0074 & 0.0088 & 0.991 & -0.019 & 0.034 \\
\hline & Koshinetsu & 0.0122 & 0.0145 & 0.991 & -0.032 & 0.056 \\
\hline & Kinki & 0.0158 & 0.0102 & 0.782 & -0.015 & 0.047 \\
\hline & Chugoku & 0.0011 & 0.0144 & 1.000 & -0.042 & 0.045 \\
\hline & Shikoku & 0.0270 & 0.0186 & 0.833 & -0.083 & 0.029 \\
\hline & Kyushu and Okinawa & 0.0045 & 0.0114 & 1.000 & -0.030 & 0.039 \\
\hline \multirow{7}{*}{ Kinki } & Hokkaido and Tohoku & 0.0050 & 0.0110 & 1.000 & -0.038 & 0.028 \\
\hline & Kanto & -0.0084 & 0.0076 & 0.955 & -0.031 & 0.015 \\
\hline & Koshinetsu & 0.0036 & 0.0137 & 1.000 & -0.045 & 0.038 \\
\hline & Chubu & -0.0158 & 0.0102 & 0.782 & -0.047 & 0.015 \\
\hline & Chugoku & -0.0146 & 0.0136 & 0.962 & -0.056 & 0.027 \\
\hline & Shikoku & -0.0428 & 0.0180 & 0.254 & -0.097 & 0.012 \\
\hline & Kyushu and Okinawa & 0.0113 & 0.0104 & 0.960 & -0.043 & 0.020 \\
\hline
\end{tabular}




\begin{tabular}{|c|c|c|c|c|c|c|}
\hline \multicolumn{7}{|c|}{ Continued } \\
\hline & Hokkaido and Tohoku & 0.0096 & 0.0149 & 0.998 & -0.036 & 0.055 \\
\hline & Kanto & 0.0062 & 0.0126 & 1.000 & -0.032 & 0.044 \\
\hline & Koshinetsu & 0.0111 & 0.0170 & 0.998 & -0.041 & 0.063 \\
\hline \multirow[t]{7}{*}{ Chugoku } & Chubu & 0011 & 0.0144 & 1.000 & -0.045 & 0.042 \\
\hline & Kinki & 0.0146 & 0.0136 & 0.962 & -0.027 & 0.056 \\
\hline & Shikoku & -0.0281 & 0.0206 & 0.874 & -0.091 & 0.034 \\
\hline & Kyushu and Okinawa & 0.0033 & 0.0145 & 1.000 & -0.041 & 0.047 \\
\hline & Hokkaido and Tohoku & 0.0377 & 0.0190 & 0.493 & -0.020 & 0.095 \\
\hline & Kanto & 0.0344 & 0.0173 & 0.488 & -0.018 & 0.087 \\
\hline & Koshinetsu & 0.0392 & 0.0207 & 0.557 & -0.024 & 0.102 \\
\hline \multirow[t]{7}{*}{ Shikoku } & Chubu & 0.0270 & 0.0186 & 0.833 & -0.029 & 0.083 \\
\hline & Kinki & 0.0428 & 0.0180 & 0.254 & -0.012 & 0.097 \\
\hline & Chugoku & 0.0281 & 0.0206 & 0.874 & -0.034 & 0.091 \\
\hline & Kyushu and Okinawa & 0.0314 & 0.0187 & 0.700 & -0.025 & 0.088 \\
\hline & Hokkaido and Tohoku & 0.0063 & 0.0121 & 1.000 & -0.030 & 0.043 \\
\hline & Kanto & 0.0029 & 0.0091 & 1.000 & -0.025 & 0.031 \\
\hline & Koshinetsu & 0.0077 & 0.0146 & 1.000 & -0.037 & 0.052 \\
\hline \multirow[t]{4}{*}{ Kyushu and Okinawa } & Chubu & -0.0045 & 0.0114 & 1.000 & -0.039 & 0.030 \\
\hline & Kinki & 0.0113 & 0.0104 & 0.960 & -0.020 & 0.043 \\
\hline & Chugoku & 0.0033 & 0.0145 & 1.000 & -0.047 & 0.041 \\
\hline & Shikoku & 0.0314 & 0.0187 & 0.700 & -0.088 & 0.025 \\
\hline
\end{tabular}

*The mean difference is significant at the 0.05 level.

ured via a heart rate variability analysis system that utilizes the camera of smartphones [8]. This system was developed by the authors during previous research. As far as the relationship between autonomic nervous system and activity, total power and sympathetic nervous activity were found to rise after waking, while during leisure time, it was found that total power rises and sympathetic nervous activity is inhibited.

Concerning the relationship between autonomic nervous system and day of the week, it was found that total power decreases from the middle through the latter part of the week (namely, Wednesday, Thursday, and Friday), while it rises on Saturday. What's more, sympathetic nervous activity is suppressed on Saturday. Regarding the relationship between autonomic nervous system and region, it was found that total power is lower in the Kanto region than in others. This study has managed to give statistical proof (using a large amount of measurement data) to ideas held by the public for years. Thus, the data can be considered meaningful to society, and the authors hope that it helps to improve work-life balance.

\section{References}

[1] Onaka, T. (2005) Stress and Its Neural Mechanisms. Journal of Pharmacological Sciences, 126, 170-173.

[2] Itao, K. and Komazawa, M. (2015) Wearable Device Applications and Technology Tends. Japan Institute of Electronics Packaging, Special Issue, 18, 384-389.

[3] Union Tool Co. (2013) Wearable Heart Rate Sensor WHS-1. http://uniontool.co.jp/product/sensor/index 02.html

[4] WIN Frontier Co. Ltd. (2013) Lifescore Quick. http://www.winfrontier.com/lifescorequick.html

[5] Fumio, M., et al. (2001) Basic Research to Estimate Athlete’s Psychological Stress Responses by Digital Plethysmo- 
graphy. Research Bulletin, 29, 87/102

[6] Task Force of the European Society of Cardiology and the North American Society of Pacing and Electrophysiology. (1996) Heart Rate Variability: Standards of Measurement, Physiological Interpretation, and Clinical Use. Circulation, 93, 1043-1065. http://dx.doi.org/10.1161/01.CIR.93.5.1043

[7] Mikio, H. (2010) Spectral Analysis. AsakuraPub, Tokyo.

[8] Komazawa, M., Itao, K. and Luo, Z. (2015) Development of Heart Rate Variability Analysis System Using a SmartPhone Camera. 20th Poster Presentation Collection of the Academy of Human Informatics, 19-20.

[9] WIN Frontier Co., Ltd. (2015r) COCOLOLO_Check 8 Types of Feelings with the Fluctuation of the Heart Rate. https://itunes.apple.com/jp/app/cocololo-cafe-kimochishea/id973325431?mt=8\&ign-mpt=uo\%3D4

[10] WIN Frontier Co., Ltd. (2015) COCOLOLO • Heart Furnace-Stress Check Using the Fluctuation of Heart Rate. https://play.google.com/store/apps/details?id=com.winfrontier.COCOLOLO\&hl=ja

[11] Kobayashi, H. (2016) COCOLOLO: Autonomic Nervous System Are Complete by the Stress Check of the Heart in 30 Seconds. GOMA BOOK Co., Ltd. http://www.goma-books.com/archives/36436

[12] Komazawa, M., Itao, K. and Luo, Z. (2015) The Relationship between Autonomic Nervous System and Age, BMI Based on about 100,000 of Measurement Data. $21^{\text {st }}$ Poster Presentation Collection of the Academy of Human Informatics, 24-25.

[13] Komazawa, M., Itao, K. and Luo, Z. (2015) The Relationship between Autonomic Nervous System and Circadian rhythm Based on about 100,000 of Measurement Data. 22nd Poster Presentation Collection of the Academy of Human Informatics, 14-15.

[14] Kuratsune, H. (2011) Creation of Chronic Fatigue Diagnosis Guidelines and the Establishment of Objective Fatigue Diagnostic Methods for Patients Complaining of Chronic Fatigue Accompanied by Autonomic Abnormalities. Health, Labor and Welfare Ministry Scientific Research, Disability Measures Research Department (Mental Disorders and Nerve and Muscle Disease Areas) 2009-2011 General Research Report, 1-114.

[15] Yukishita, T., Lee, K., Kim, S., Yumoto, Y., Kobayashi, A., Shirasawa, T. and Kobayashi, H. (2010) Age and Sex-Dependent Alterations in Heart Rate Variability: Profiling the Characteristics of Men and Women in Their 30s. Anti-Aging Medicine, 7, 94-100. http://dx.doi.org/10.3793/jaam.7.94

[16] Shimizu, T. (2008) The Autonomic Function around the Clock. Japanese Society for Medical and Biological Engineering, 46, 154-159.

[17] Ministry of Health, Labour and Welfare. http://ibaraki-roudoukyoku.jsite.mhlw.go.jp/library/ibaraki-roudoukyoku/corner_kantoku/kantoku12_02.pdf 